\title{
Integrating a New Service: One Library's Experience with Digital Reference
}

\author{
by Susan Herzog
}

$\mathbf{R}$ ecently I completed answering a two-page list of questions from a Virginia library that was planning digital reference service. Their concerns reminded me where the Public Library of Charlotte and Mecklenburg County (PLCMC) was about two years ago, when we began to consider virtual reference.

Digital reference - virtual reference - e-reference - chat reference - we were just starting to read about this new service, wondering if customers would really use it. The first step was to send staff to the second Virtual Reference Desk Conference held in Seattle in the fall of 2000, and to the pre-conference offered at ALA Midwinter in Washington, D.C., in January 2001.

As we became more familiar with the concept and with the various software products available at that time, we began to understand how digital reference could increase our reference services, reach new customers, and expand PLCMC's electronic capabilities.

The rest of that spring was spent reading many articles cited in several lengthy bibliographies we received at the conferences. We met with our Web Services department and made the decision to find a product requiring very little customizing as they were busy developing several new service Web sites. That decision eliminated several products that would have required many hours of tinkering and adjusting by Web Services staff.

By September 2001, three staff members had come forward, who were very enthusiastic about digital reference and who carefully tested our top three products from both the staff and the patron's perspectives. Two products were very similar, so our final choice was determined by price and the superb customer service we received.

In October 2001, we signed the contract with 24/7 Reference. I knew a coalition of California libraries had been developed, but didn't realize that libraries outside of California could be part of the coalition. When I discovered that PLCMC could be part of the coalition by monitoring the queues for just ten hours a week, I was elated. We could provide our patrons with access to virtual reference 24 hours a day, seven days a week, and solve the scheduling problems I had envisioned. We were asked whether we'd be willing to take 2:00 to 4:00 p.m. Monday through Friday. That's lunchtime on the West Coast so those hours were harder for them to cover. Those afternoon hours were perfect for us!

During November and December 2001, we trained twelve librarians in the Information Services department of the Main Library, and the five high-level paraprofessionals in Telephone Reference, a separate section within the department. I knew we wouldn't need that many staff to monitor the service, but I did want them all to know how it worked. Susan McGlamery, who developed the LSTA grant that established 24/7 Reference for use in the Metropolitan Cooperative Library System located in southern California, flew to Charlotte for a full-day training session. We also used the training modules that were posted on the $24 / 7$ Reference Web site.

In January 2002, we got the bright idea that for the last two weeks of the month we would ask every librarian in the PLCMC system (75-80 librarians in 24 branch libraries) to send us questions from 2:00 to 4:00 p.m., simulating what we thought it would be like when we went live. What we had not planned on 
was that half of those folks would send in their questions on the very first day!

We had paired staff so one person monitored the $24 / 7$ training queue, while the other could help find the answer. The first day of this experiment almost everyone, who was not on a public desk, was standing by to help, if needed. The person, who was actually connected with the patron asking the question, had to maneuver through the software, trying to remember each step. The first couple of staff came away from this experience dripping wet, after frantically watching the little box show that first one, then two, then five, and more questions were waiting to be answered.

By the time we went live - February 25, 2002 - it was almost a let-down when the questions came in at a nice even tempo. For the first three or four months, two staff worked together answering questions. Now, a full year later, each works alone, taking the full twohour shift.

What have we learned?

- We get the same questions in virtual reference that we get on the phones, through e-mail, and at the desk.

- I thought e-mail service would drop considerably, but it continues to grow. We're averaging 185 e-mails a month now, with 465 questions through $24 / 7$. The total for 24/7 includes not only the questions staff answer but also the questions that PLCMC patrons ask the coalition. We average 2.3 questions each hour that we monitor the service, spending an average of 14 minutes to answer a question.

- We have yet to scan anything from a print resource to send to someone during a chat session.

- I had staff develop all sorts of bibliographies and pathfinders to show how to research various popular topics, thinking we would push these pages to patrons. So far we have not pushed a single page.

- It really is all about the Internet and electronic databases. Even a simple Google search will give some search terms to help you get started. PLCMC has developed several service Web sites (Bizlink.org, for example) that we use. 24/7 Reference also has a group of shared databases that all members of the coalition can use.

- Survey results show that $75-85 \%$ of people using this service like it and plan to use it again.

- Neither our Web Services or Information Technology departments had to do much to help staff work with this service, once we upgraded our computers. The librarians' PCs need at least $256 \mathrm{mb}$ of RAM and a $200 \mathrm{mhz}$ or faster Pentium class processor. The software uses Java applets and Active X, so browsers need to be Java-enabled. Web Services designed the opening page on the PLCMC Web site (www.plcmc.org -click on the $24 / 7$ logo) to show people the various ways they can ask us a question.

- Technical glitches have been handled easily by the 24/7 Reference staff in California.

- Quality control occurs when the team leader, Martin House, and I review transcripts of the questions answered by our staff. We also review transcripts produced when other libraries within the coalition answer questions from PLCMC patrons. The review of transcripts gives us opportunities for continuous training as we work with staff to improve customer service.

- There have been few complaints when a Charlotte patron has had a question answered by a California librarian. Library-specific questions (genealogy or some circulation issues, for example) are easily forwarded as e-mail questions.

After reviewing the questions asked by the Virginia library, I could honestly say that the whole process was remarkably easy, with very few problems. We were fortunate to have the right staff in place, who quickly became quite nimble at using chat reference, and a vendor, who had worked through a lot of our concerns with other libraries. After 16 months of offering digital reference to PLCMC patrons, answering digital reference questions has become just another way of doing business! 